\title{
PESQUISANDO A FAMÍLIA: A EXPERIÊNCIA DA ENFERMAGEM NA UFSC
}

\author{
RESEARCHING FAMILY: THE EXPERIENCE OF NURSING AT UFSC
}

Coleta Rinaldi Althoff ${ }^{1}$

RESUMO: Apresenta uma análise das dissertações e teses que têm como foco a família, apresentadas ao Programa de Pós Graduação em Enfermagem da Universidade Federal de S anta Catarina. Procura mostrar os tipos de pesquisa, o objeto de estudo e referencial teórico utilizado, ressaltando a compreensão da família na enfermagem. Reconhece-se que as práticas assistenciais, enquanto tipo de pesquisa desenvolvida no Curso de Mestrado, tem possibilitado abordar a família como unidade.

PALAVRAS CHAVE: Enfermagem; Pesquisa; Família.

\section{INTRODUÇÃO}

A família em nossa sociedade, constitui uma unidade básica e complexa, com ampla diversidade de estruturas e formas de organizar o seu modo de vida. Na complexidade do processo de viver do ser humano, a família é algo muito especial e para a maioria das pessoas, ela é a coisa mais importante. Este ponto de vista parece estar ligado às diversas funções que a família exerce, entre elas, o cuidado da saúde de seus membros. Mas, o que conhecemos a respeito desta função exercida pela família?

A prática com famílias é uma atividade exercida pela enfermagem desde os seus primórdios, mas durante muitos anos, a enfermagem tradicionalmente vem centrando os seus estudos no indivíduo. A família, entretanto, percebida como cuidadora e participante do processo saúde e doença, tem despertado o interesse dos enfermeiros. Para Elsen (1994,p.71-72) a família "tem um referencial para compreender e atuar nas diferentes situações de saúde e doença e que há evidências de que a família funciona como uma unidade de saúde para os seus membros, o que leva a enfermagem a enfrentar um novo desafio de cuidar de quem cuida". Este desafio torna-se ainda maior, quando se pensa que este cuidar exige conhecer como a família cuida. Não existem famílias iguais. A família, por sua própria natureza, é complexa, distinta e extremamente dinâmica, cujos processos desenvolvidos dentro do grupo, de cada membro pertencente ao grupo e deste com a comunidade e com a sociedade, contribuem para facilitar ou perturbar a saúde. Na dinâmica da vida familiar, entretanto, existem aspectos que são inerentes ao processo de viver da maioria das famílias. 0 caminho para a compreensão do que isso significa ou o que pode fundamentar o modo de vida e as práticas cotidianas frente a singularidade de cada grupo familiar, constitui-se um foco de investigação na área.

A pesquisa com a família tem sido objeto de estudo de várias autoras americanas, revelando um crescimento substancial de artigos publicados, nos quais são identificados os diferentes aspectos que envolvem a família e a pesquisa, através de uma análise crítica dos estudos nesta área de conhecimento. Feetham (1984) na revisão das pesquisas sobre a família, verificou que os pesquisadores apresentavam um grande interesse com relação ao papel dos membros da família, a solidariedade familiar, os padrões de comunicação e a estrutura familiar. A autora observou também que nas várias pesquisas analisadas, a família era vista como ambiente do indivíduo e que outros estudos reconheciam a interdependência da família com o ambiente, nas relações com a estrutura social e o sistema de saúde. Declarou ainda que poucos relatórios consideravam a família como uma unidade. A partir deste estudo, Whall e Loveland-Cherry (1993), resolveram analisar as pesquisas que tinham como foco principal, a família como unidade.

Professora Adjunta. Departamento de Enfermagem da Universidade Federal de Santa Catarina. Membro do GAPEFAM- Grupo de Assistência, Pesquisa e Educação na Área de Saúde da Família. 
As autoras verificaram que a saúde relacionada a estrutura familiar constituía o objeto de interesse de grande parte dos estudos, enquanto que outros se voltaram para os aspectos culturais ou às necessidades da família em situação de doença. Concluíram que, embora tenha aumentado a quantidade de estudos nesta área, a família como unidade de análise, ainda não está explicitamente definida.

Gillis (1989), ao verificar que quase $90 \%$ dos estudos analisados, tinham como foco a díade familiar, mãe e filho, pai e filho ou casal, comenta que o grande número de estudos na área maternal-infantil são identificados como de famílias, constituindo um reflexo da perspectiva tradicional de definir família. Este aspecto também é apontado por Mercer (1989), ao declarar que historicamente os profissionais de saúde tem focalizado o indivíduo ou as díades e a família tem sido vista como parte do contexto onde ocorre o tratamento ou estudo. Algumas vezes, a mãe é fonte primária dos dados e os resultados indicam apenas a percepção dela em relação a família. Ao buscar na literatura as pesquisas sobre família, observa-se a presença de um grande número de estudos que reportam esta visão, às vezes a inclusão da palavra família no título ou no conteúdo do trabalho nem sempre indica um estudo de família.

Focalizar a família como uma unidade tanto na prática quanto na pesquisa tem sido uma tarefa difícil. Reconhece-se que a família é significante para a saúde de seus membros, entretanto, quando a família é vista com uma unidade, é essencial um novo nível de entendimento e a necessidade de ampliar estes conhecimentos, na busca de uma maior clareza da sua realidade. Neste momento, torna-se importante acompanhar como este conhecimento está sendo produzido, de modo a contribuir para o desenvolvimento do campo da enfermagem familiar e alcançar resultados eficazes no desempenho das ações práticas.

O Programa de Pós-graduação em Enfermagem da Universidade Federal de Santa Catarina, tem o compromisso de formar e aprimorar profissionais empenhados com o avanço do conhecimento para o exercício de atividades nas áreas de enfermagem e saúde em geral. Iniciado em 1976, o Curso de Mestrado em Enfermagem, ele vem apresentando uma produção científica importante, concretizada também pelas teses elaboradas no Curso de Doutorado, implantado em 1993. Desde seu início até o ano de 1998, foram defendidas e apresentadas 182 dissertações de mestrado e 26 teses de doutorado, das quais 34 pesquisas focalizaram a família.

\section{OBJ ETIVO}

Este trabalho tem como objetivo fazer um levantamento e a análise dos estudos realizados sobre a família nos cursos de pós-graduação da Universidade Federal de Santa Catarina.

\section{UM OLHAR SOBRE AS PESQUISAS NA ÁREA DE FAMÍLIA.}

Ao dirigir um olhar sobre os estudos realizados como conclusão dos cursos de pós-graduação, verificouse que 0 interesse em estudar as famílias em nosso meio, começou em 1985, quando deu-se início ao desenvolvimento de uma pesquisa sobre conceitos e práticas de saúde das famílias catarinenses, coordenada pela Dra. Ingrid Elsen, recém chegada do Curso de Doutorado em Ciências da Enfermagem, realizado na Universidade da Califórnia-USA, onde defendeu a tese sobre Conceptts of Health and IIness and Related behaviors among families living in a Brazilian fishing village, com dados obtidos no Brasil. De forma integrada vários projetos foram gerados entre os docentes, discentes e profissionais. Entre estes, um deu origem ao primeiro estudo sobre família realizado dentro de uma abordagem etnográfica, no curso de Mestrado( Cartana, 1988). No mesmo ano, Franco(1988) apresentou um estudo exploratório, tendo como foco a situação do familiar que acompanha um membro da família hospitalizado. Até então a família era vista como parte do contexto do indivíduo. A partir de 1989, as dissertações passaram a ser realizadas através de práticas assistênciais, considerada como pesquisa prática de acordo com a classificação de Demo (1994). 0 interesse pela área da família cresceu e família considerada como uma unidade começou a ser percebida. Durante os últimos anos outros tipos de pesquisa também surgiram, enfocando a família em seus diferentes aspectos.

0 envolvimento dos profissionais com a saúde da família em nosso meio, aumentou nos últimos tempos e com isso a geração de novos conhecimentos. Dentro deste contexto perguntamos: Como está sendo construído este conhecimento? Que tipo de pesquisas estão sendo realizadas? Qual o objeto de estudo? Qual é a visão da enfermagem sobre a família? 


\section{RESULTADOS E DISCUSSÃO}

Para a elaboração do estudo foi realizado um levantamento das dissertações de mestrado e teses de doutorado nos cursos de pós-graduação em enfermagem, que tinham como foco a família. Surgiram então os estudos de Patrício (1990), Ribeiro (1990), Boehs (1990), Ghiorzi (1991), Nietschke (1991), Mattos (1992), Koller (1992), Pelzer (1993), Monticelli (1994), Dall Sasso (1994), Carraro (1994), Beck (1995), Batista (1995), Cereser (1996), Silva (1996), Lacerda (1996), Bielmann (1997), Motta (1997), Sandri (1997), Diniz (1997), Grudtner( 1997), Carraro( 1998), Waidman (1998), Santos( 1998), Marcon( 1998), Schwartz (1998), Morais (1998), Marcês (1998), Trevisan (1998), Padoim (1998), Centa( 1998).

Através de uma abordagem reflexiva, realizou-se a análise sobre as informações obtidas nos relatórios, cujos resultados são apresentados segundo o tipo, objeto de estudo, refencial teórico e a compreensão de família.

\section{Tipo de Estudos}

Ao conceber uma pesquisa, o pesquisador se preocupa em delinear o estudo através de um processo apropriado para compreender um determinado fenômeno. Nos estudos realizados verificou-se a presença de diferentes tipos e objeto de estudo, apresentados no quadro 1.

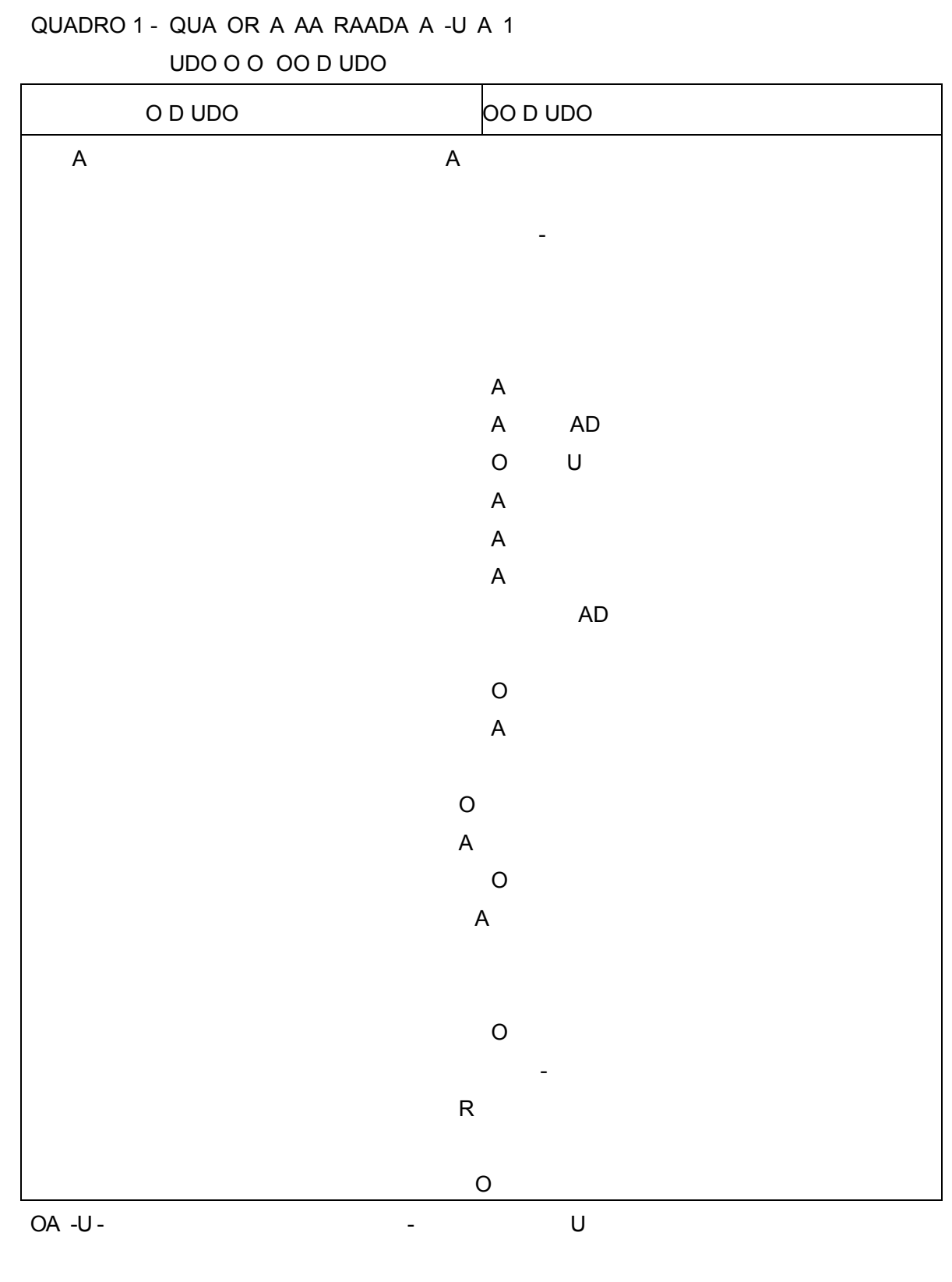


Observa-se que a maioria dos estudos realizados durante o período de desenvolvimento dos cursos está relacionada com as práticas assistencias, que constitui na elaboração e a aplicação de uma proposta metodológica, com uma fundamentação teórica. Esse tipo de estudo é um gênero de investigação denominado de pesquisa prática, que de acordo com Demo (1994, p.38), é "destinada a intervir diretamente na realidade, a teorizar práticas, a produzir alternativas concretas, a comprometer-se com soluções". 0 desenvolvimento deste tipo de pesquisa tem favorecido a compreensão da realidade da família, possibilitando a troca de experiências entre o profissional e o cliente, de modo a direcionar as ações de enfermagem. A prática assistencial possibilitou um novo olhar para a família. Ela não é mais vista como parte do ambiente do indivíduo, mas como uma unidade com capacidades, limitações e potencialidades para viver com saúde.

Segundo Demo (1994, p.38), "a prática tem lugar próprio, embora sempre dialéticamente imbricado na teoria, correspondendo sobretudo ao intento inovador da ciência, que pretende não esgotar-se na compreensão da realidade, mas transformá-la". Com a aplicação dessa modalidade, constata-se que é possível desenvolver estudos que estejam comprometidos com a transformação da prática, favorecendo a interação entre os participantes e possibilitando a troca de saberes. Por outro lado, as pesquisas do tipo exploratória e bibliográfica buscam ampliar o conhecimento, enquanto que a metodológica está voltada para a análise de aspectos importantes, como a clareza de conceitos e a reflexão profunda de um aspecto da vida familiar.

Entre os estudos realizados até o momento, verifica-se que dois estudo respaldaram-se na fenomenologia. Enquanto um utilizou esta perspectiva filosófica como suporte para pensar a família dentro da dimensão do processo saúde-doença, o outro procurou conhecer o ser familiar em uma situação crítica. 0 desenvolvimento de um a teoria substantiva foi outro tipo de estudo que possibilitou conhecer a família em situação de infertilidade, revelando a importância das relações familiares na busca de uma solução.

Quanto ao objeto de estudo, os pesquisadores realizaram as investigações em diferentes fases do ciclo de vida familiar, revelando as relações e o cuidado da família com o recém-nascido, o adolescente, 0 adulto, 0 idoso e entre as gerações. Além disso, os interesses estiveram voltados para certos eventos como 0 nascimento, a criação, a doença, a violência, a internação hospitalar e a morte, mostrando a organização familiar no atendimento das necessidades, os aspectos sociais, culturais e a busca de solução para os problemas surgidos durante o transcorrer dos próprios eventos. Tanto a família em sua dimensão temporal, quanto as experiências nos diversos eventos da vida familiar, são descobertas importantes para a Enfermagem, no sentido de capacitar e redefinir o trabalho com as famílias. Wrigt \& Leakey (1990) declaram que a Enfermagem tem necessidade de entender a ligação entre a dinâmica familiar e o processo saúde-doença, tanto do ponto de vista teórico quanto prático.

Olhando atentamente para os estudos, observa-se que o pesquisador buscou através da presença dos eventos, uma entrada para se aproximar da família. No momento essa parece ser a maneira de conhecer a família, observar como ela se comporta frente a situação e de como procura resolver os seus problemas. Neste contexto, a enfermeira começa a entender a família como uma unidade, seu funcionamento, a dinâmica, os valores, as práticas, os rituais, as forças e os papéis.

O referencial teórico na pesquisa com as famílias.

O utra questão importante para o desenvolvimento da pesquisa é a fundamentação teórica, representando o centro ou a estrutura teórica que direciona e orienta o pesquisador quanto a compreensão do fenômeno estudado. Nos últimos tempos, a Enfermagem vem utilizando referenciais baseados nos conceitos empregados em suas próprias teorias ou e teorias de famílias, assim como abordagens teóricas de outras disciplinas, como a Psicologia e as Ciências Sociais. Para Elsen (1994, p.63), "as teorias e marcos conceituais desenvolvidos na enfermagem e em outras áreas do conhecimento tem vindo em auxílio do profissional em sua tentativa de abordar a família. Eles não oferecem apenas conceitos diferentes de família, mas perspectivas teóricas que possibilitem compreender a família, seus mundos internos, bem como as suas relações com as demais instituições sociais". Para a abordagem das linhas teóricas de família observadas nos estudos, a presentamos no quadro 2 somente as identificadas nas pesquisas práticas. 
QUADRO 2 - LINHAS TEÓRICAS ABORDADAS NO REFERENCIAL DAS PESQUISAS PRÁTICAS

\begin{tabular}{|c|c|c|}
\hline LINHA TEÓRICA REFERENCIAL & ESTUDOS & AUTORANO \\
\hline \multicolumn{2}{|c|}{ 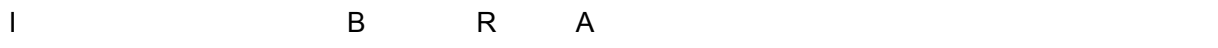 } & $\mathrm{R} \square \square \square \square \square \square$ \\
\hline & $\mathrm{N} \square \square \square \square \square \square \square \square \square$ & 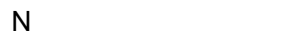 \\
\hline 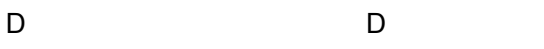 & 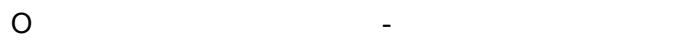 & $\mathrm{B} \square \square \square \square \square \square \square \square$ \\
\hline \multirow[t]{2}{*}{ 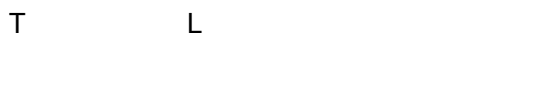 } & 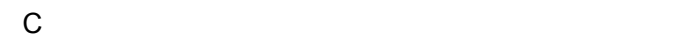 & $\mathrm{P} \square \square \square \square \square \square \square \square$ \\
\hline & 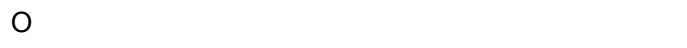 & 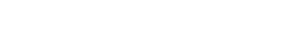 \\
\hline 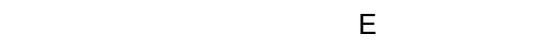 & 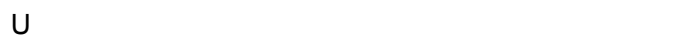 & 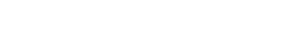 \\
\hline S & 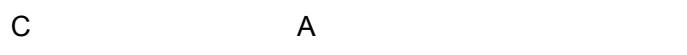 & 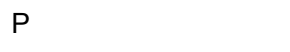 \\
\hline \multirow[t]{2}{*}{$\mathrm{C} \square \mathrm{C} \square \square \square \square$} & A & $\mathrm{D} \square \square \mathrm{S} \square \square \square \square \square \square \square \square$ \\
\hline & 四口血 & \\
\hline 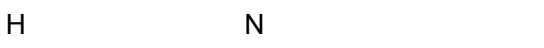 & 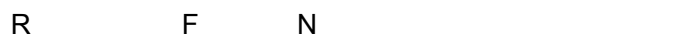 & $\mathrm{C} \square \square \square \square \square \square \square \square \square$ \\
\hline $\mathrm{H} \square \square \square-(\square \square-\square \square \square \square \mathrm{P} \square \square \square \square$ & O & 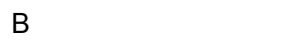 \\
\hline 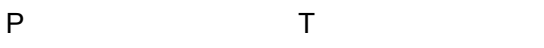 & 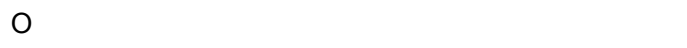 & $\mathrm{B} \square \square \square \square \square \square \square$ \\
\hline 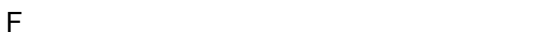 & 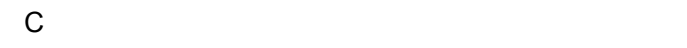 & $\mathrm{L} \square \square \square \square \square \square \square \square \square$ \\
\hline \multicolumn{2}{|c|}{ 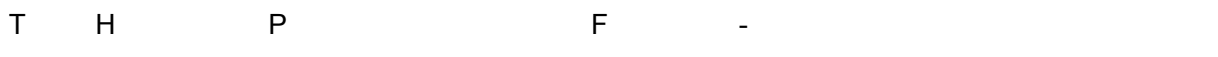 } & $\mathrm{P} \square \square \square \square \square \square \square$ \\
\hline & 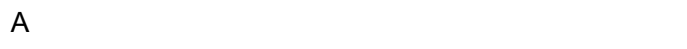 & $\mathrm{S} \square \square \square \square \square \square \square \square$ \\
\hline 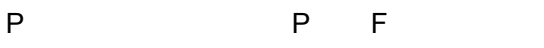 & 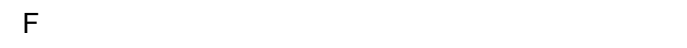 & $\mathrm{D} \| \mathrm{m} \square \square \square \square$ \\
\hline 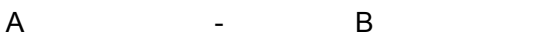 & 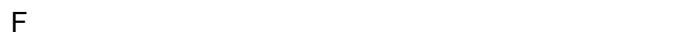 & 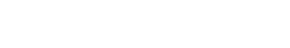 \\
\hline 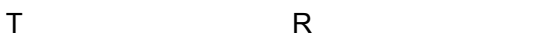 & 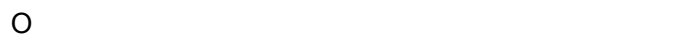 & 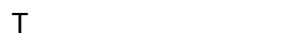 \\
\hline \multicolumn{3}{|l|}{$\mathrm{C} \square \square \square \square \square \square \square \square \square \square-\mathrm{C} \square \square \square \square \square$} \\
\hline 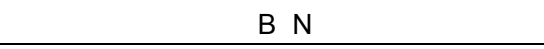 & 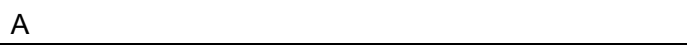 & $\mathrm{S} \square \square \square \square \square \square \square$ \\
\hline
\end{tabular}

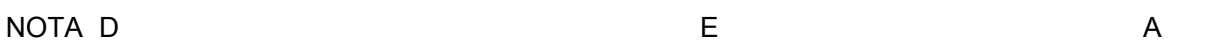

Verifica-se que a Enfermagem tem transitado em diversas linhas teóricas, utilizando de maneira parcial as teorias tanto as da Enfermagem quanto as de outras disciplinas, adaptando os conceitos ao fenômeno estudado. 0 quadro apresentado acima possibilita ter uma visão de que diferentes referenciais teóricos podem ser utilizados quando adequados a situação ou fenômeno que se queira estudar. Certamente a escolha do referencial se deu a partir da análise das teorias existentes, relacionando-os às questões formuladas. A tarefa de selecionar um referencial teórico exige do pesquisador uma reflexão e uma definição da sua visão de mundo, crenças e valores sobre a família e a Enfermagem (Elsen, 1994). Q uanto a utilização parcial das teorias nas investigações realizadas pelos enfermeiros, parece que ainda não há estrutura apropriada para compreender os fenômenos da realidade familiar, sendo necessário a adaptação. Segundo Feetham (1984) isto constitui uma limitação primária encontrada na maioria das pesquisas. Talvez este tipo de estudo não se caracterize como apropriado para testar teorias, porém tem permitido avançar no conhecimento da Enfermagem e principalmente apontar caminhos para a prática com famílias.

Ao adaptar as idéias propostas pelas teorias, tanto as da própria Enfermagem quanto as de outras disciplinas ao objeto e ao objetivo da investigação, o pesquisador estará possibilitando o encontro de novas perspectivas teóricas, permitindo avançar o conhecimento na área e apontar caminhos para a prática.

Como elemento do referencial, o conceito de família tem sido incorporado em sua estrutura teórica. Este aspecto é muito importante, porque reflete a visão de mundo do enfermeiro em relação a compreensão da família. A busca de uma definição e conceituação da família tem sido uma tentativa realizada por várias disciplinas, cada uma com o seu modo de ver família neste mundo. A Enfermagem nas últimas décadas desenvolveu várias teorias que embora tenham sido originalmente elaboradas tendo como foco o indivíduo, atualmente busca incluir a família em suas estruturas, na tentativa de compreendê-la como uma unidade.

Alguns dos estudos aqui analisados, apresentam em seu referencial teórico o conceito de família e ao direcionar o olhar sobre esses conceitos, verifica-se que as suas descrições estão voltadas para algumas formas de compreender a família como: sistema, unidade de relações, espaço de amparo e vínculo.

Ao focalizar a família como um sistema, as autoras descreveram:

"um sistema social semi-aberto, composto por indivíduos ligados por compromisso mútuo, que interagem entre si no desempenho de papéis estruturados pela cultura e sociedade".( Duwall apud Cartana, 1988, p.18). 
"um sistema interpessoal (...) dinâmico (...) assume formas, tarefas e sentidos a partir de um sistema de crenças normas (...) com influências e determinações do ambiente em que vive..."( Patrício, 1990, p.74).

"representada por um sistema social constituída por indivíduos que mantém um conjunto de reservas físicas, psíquicas e socioculturais e de ambiente físico que permitem normatizar sua vida..."( Koller, 1992, p.31).

“... um sistema social (...) possui uma estrutura própria, diferenciada dos membros que a constituem, exercendo influência e sendo por eles influenciada..."( Dall Sasso, 1994, p.94).

A visão de família como unidade de relações é descrita da seguinte forma:

"uma unidade de interações pessoais"( Burgers apud Ribeiro, 1990, p.48).

"uma instituição social, um todo articulado e relacional, construído pelo homem social ativo, permeada pela estrutura social de classes"(Ghiorzi, 1991, p.89).

"unidade de seres humanos ligados por laços de casamento, afinidade, afeto, nascimento ou adoção que interagem entre si (...) agem e reagem através do uso de símbolos"( Nietschke, 1991, p.66).

"unidade dinâmica, constituída por pessoas que se percebem como família, com certo tempo de convívio, constituindo uma história de vida"( Beck, 1995, p.44).

A família como o espaço de amparo é assim descrita:

"o lugar do afeto, da proteção"( Silva, 1996, p.114).

“o primeiro referencial do homem"( Batista, 1995, p.60).

“é a esfera íntima da existência que se une por laços consangüíneos ou por afetividade os seres humanos (...) fonte primária de suporte social"( Pelzer, 1993, p.38).

A família como vínculo:

“a família é o principal vínculo da criança com o mundo"( Morais, 1998, p.124).

Embora os conceitos apresentados nos estudos analisados possam ser agrupados, revelando um conjunto de idéias sobre a família, penso que não há limites demarcados. Acredito que o conceito de família é pela sua própria natureza, dinâmico no tempo e no espaço. A falta de clareza para a operacionalização talvez seja uma das limitações nas pesquisas, principalmente quando tratamos da família como uma unidade, com suas particularidades, suas diferenças e participante como grupo social na comunidade e de forma mais ampla na sociedade. Entretanto é preciso realizar muitas investigações para que se possa fazer o uso apropriado dentro do contexto em que a família e o pesquisador estejam inseridos.

\section{CONSIDERAÇÕES FINAIS}

Ao produzir um conhecimento através das pesquisas, tenta-se descobrir novas formas de ver e compreender a família no mundo e de buscar um caminho que possibilite uma direção para a prática da Enfermagem no contexto da família. A pesquisa voltada para a família envolve inúmeros aspectos da natureza humana, extremamente complexos, tornando-se difícil compreendê-la em sua totalidade. 0 pesquisador, entretanto, deve enfrentar o desafio de encontrar respostas para as questões que emergem do cotidiano da vida familiar.

Segundo Silva( 1998, p.274), há necessidade de realizar estudos que "visem aprofundar o conhecimento sobre o cotidiano das famílias (...) e de investigar a influência e os efeitos que uma atuação da enfermagem familial, teria sobre o cotidiano das famílias e em suas interfaces com o processo saúde-doença".

0 esforço de construir um conhecimento sobre a Enfermagem e a família, utilizando diferentes tipos de pesquisa e de referenciais teóricos, evidenciou o interesse dos enfermeiros pela descoberta de um caminho de ligação entre a teoria e a prática, na construção social da realidade. Nas pesquisas com as famílias ainda encontramos muitas limitações, desde a compreensão da família como uma unidade social com característica própria desenvolvidas no contexto, técnicas para o levantamento de informações que possibilitem uma aproximação da família em sua totalidade, a falta de instrumentos válidos e confiáveis apropriados à situação, até a tabulação e a análise dos dados que permitam esclarecer a complexidade das informações.

Embora algumas vezes, os termos família e familiar se confundam como objeto do estudo, dificultando a compreensão do foco, se está sendo dirigido para a família ou para o indivíduo, é importante seguir em frente, 
passo a passo e enfrentar os obstáculos e os desafios do conhecimento. Gillis (1991), ao refletir sobre a teoria e a prática da pesquisa de Enfermagem com famílias comenta, nós precisamos debater sobre a natureza e 0 núcleo do nosso trabalho, mostrar os reais resultados de nossa prática de Enfermagem à família, pois estes oferecem uma base importante para o desenvolvimento teórico.

Deste modo, é importante que se desenvolva estudos voltados para esta área e se promova um diálogo crítico entre os interessados, a fim de contribuir para o desenvolvimento de uma enfermagem para a saúde da família.

ABSTRACT: In this report it is presented an analysis of the dissertations and thesis presented to the Graduate P rogram in Nursing of UFSC, which have the family as focus. It is shown the types of researches, the subject of study and the theorical models used, emphasizing the comprehension of family in nursing. It is recognized that assistential practices, a type of developed within the Graduate Program, make it possible to approach family as a unit.

KEY WORDS: Nursing; Research; Family.

\section{REFERÊNCIAS BIBLIOGRÁFICAS}

1. BATISTA, Carmem Lilian B. M. Convivendo e compreendendo: assistência de enfermagem ao paciente e sua família no serviço de emergência. Florianópolis, 1995. Dissertação (Mestrado em Enfermagem) - Programa de Pós-Graduação em Enfermagem, Universidade Federal de Santa Catarina.

2. BECK, Carmem Lúcia Colomé. O processo de viver, adoecer e morrer: reflexões com familiares da pacientes internados em UTI. Florianópolis, 1995. Dissertação (Mestrado em Enfermagem) - Programa de Pós-graduação em Enfermagem, Universidade Federal de Santa Catarina.

3. BIELEMANN, Valquíria de Lourdes M. O ser com câncer: uma experiência em família. Florianópolis, 1997. Dissetação (Mestrado em Enfermagem-polo UFPL) - Programa de Pós-graduação em Enfermagem, Universidade Federal de Santa Catarina.

4. BOEHS, Astrid E. Prática do cuidado ao recém-nascido e sua família, baseado na teoria transcultural de Leinniger e na teoria do desenvolvimento da família. Florianópolis, 1990. Dissertação (Mestrado em Enfermagem) - Programa de Pós-graduação em Enfermagem, U niversidade Federal de Santa Catarina.

5. CARTANA, Maria do Horto F. Rede e suporte social de famílias, Florianópolis, 1988. Dissertação (Mestrado em Enfermagem) - Programa Pós-graduação em Enfermagem, Universidade Federal de Santa Catarina.

6. CARRARO, Telma E. Resgatando Florence Nightingale: a trajetória da enfermagem junto ao ser humano e sua família na situação cirúrgica. Florianópolis, 1994. Dissertação (Mestrado de Enfermagem) - Programa de Pós-graduação de Enfermagem, Universidade Federal de Santa Catarina.

7. CARRARO, Vanderley. O ser humano inconsciente: como o seu familiar o compreende. Porto Alegre, 1998. Dissertação (Mestrado em Enfermagem) - Polo Expansão-UFRGS. - Programa de Pós-graduação em Enfermagem, Universidade Federal de Santa Catarina.

8. CENTA, Maria de Lourdes. Do natural ao artificial: a trajetória do casal infértil em busca do filho desejado. Florianópolis, 1998. Tese (Doutorado em Filosofia de Enfermagem) - Programa de Pós-graduação em Enfermagem, Universidade Federal de Santa Catarina.

9. CERESER, Helena Luiza. A vivência familiar da mulher com hipertensão arterial. Florianópolis, 1996. Dissertação (Mestrado em Enfermagem) - Polo Santa Maria, Programa de Pós-graduação em Enfermagem, U niversidade Federal de Santa Catarina.

10. DALL SASSO, Grace T. M. A crise como uma oportunidade de crescimento para a família que enfrenta uma doença aguda - um desafio para a enfermagem. Florianópolis, 1994. Dissertação (Mestrado em Enfermagem) - Programa de Pós-Graduação em Enfermagem, Universidade Federal de Santa Catarina.

11. DEMO, Pedro. Pesquisa e construção de conhecimento. Rio de J aneiro : Tempo Brasileiro, 1994.

12. DINIZ, J osé Claudio. Enfermagem: uma proposta para atuar com famílias de indivíduos alcoolistas baseado no método de Paulo Freire. Itajaí, 1997. Dissertação (Mestrado em Enfermagem) - Programa de Pós-Graduação de Enfermagem, Universidade Federal de Santa Catarina.

13. ELSEN, Ingrid. Saúde familiar: a trajetória de um grupo. In: ELSEN, Ingrid et al. Marcos para a prática com famílias. Florianópolis : Editora da UFSC, 1994. cap.2 p.61-77.

14. ELSEN, I. Conceptts of health and illness and related behaviors among families living in a Brazilian fishing village. San Francisco, 1984. Tese (Doutorado em Enfermagem) Curso de Doutorado em Ciências de Enfermagem, Universidade da Califórnia.

15. FEETHMAN, Suzane L. Family R esearch: issues e directions for nursing. In: Annual Review of Nursing Research. New York : Springer-Verlag, 1984, p.3-35.

16. FRANCO, Maria Celsa. Situações do familiar que acompanha um paciente adulto internado em hospital geral. Florianópolis, 1988. Dissertação (Mestrado em Enfermagem) - Programa de Pós-Graduação de Enfermagem, Universidade F ederal de Santa Catarina.

17. GHIORZI, Angela da Rosa. Possibilidades e limites para uma prática transformadora em enfermagem familiar. Florianópolis, 1991. Dissertação (Mestrado em Enfermagem) - Programa de Pós-Graduação em Enfermagem, Universidade de Santa Catarina. 
18. GILLIS, Catherine L. Family research in nursing. In: GILLIS, Catherine L et.al. Toward a science of family nursing. Mento Park, California : Addison-Wesley Publishing 1989, cap.3,p.37-48.

19. GILLIS, Catherine L. Family nursing research, theory and practice. Image: J ournal of Nursing Scholarship, Indianópolis, v.2, n.1, p.19-22, 1991.

20. GRUDTNER, Dalva Irany. Processo educativo participativo com enfoque na ajuda à família: uma experiência na disciplina de enfermagem cirúrgica. Florianópolis, 1997. Dissertação (Mestrado em Enfermagem) - Programa PósGraduação em Enfermagem, Universidade Federal de Santa Catarina.

21. KOLLER, Evely M.P. A prática do cuidar/cuidado no cotidiano do cliente/família sob o impacto do vírus HIV. Florianópolis, 1992. Dissertação (Mestrado em Enfermagem) - Programa de Pós-Graduação em Enfermagem, Universidade Federal de Santa Catarina.

22. LACERDA, Maria Ribeiro. O cuidado transpessoal de enfermagem no contexto domiciliar. Curitiba, 1996. Dissertação (Mestrado em Enfermagem) - Polo UFPR, Universidade Federal de Santa Catarina.

23. MARCON, Sonia Silva. Criar os filhos: experiência de família de três gerações. Florianópolis, 1998. Tese (Doutorado em Filosofia da Enfermagem) - Universidade Federal de Santa Catarina

24. MERCER, R. Theoretical perspectives on the family. In. GILLIS, Catherine L. et al. Toward a science of family nursing. California : Mento Park. Addison-Wesley. 1989, p.9-36.

25. MERCES, Nen Nalú Alves das. As representações sociais do câncer: enfermos e famílias compartilhando uma jornada. Florianópolis, 1998. Dissertação (Mestrado em Enfermagem) - Programa de Pós-Graduação em Enfermagem, Universidade Federal de Santa Catarina.

26. MONTICELLI, Marisa. Nascimento como um rito de passagem: uma abordagem cultural para o cuidado à saúde das mulheres e recém-nascidos. Florianópolis, 1994. Dissertação (Mestrado em Enfermagem) - Programa de PósGraduação em Enfermagem, Universidade F ederal de Santa Catarina.

27. MORAIS, Eliane P inheiro de. Negligência nos cuidados de saúde com crianças e adolescentes: uma proposta para atuação da enfermeira com famílias. Florianópolis, 1998. Dissertação (Mestrado em Enfermagem) - Programa de PósGraduação em Enfermagem, Universidade Federal de Santa Catarina.

28. MOTTA, Maria da Graça C. O ser doente no tríplice mundo da criança, família e hospital: uma descrição fenomenológica das mudanças existenciais. Florianópolis, 1997. Tese. (Doutorado em Filosofia da Enfermagem) Programa de Pós-Graduação em Enfermagem, Universidade Federal de Santa Catarina.

29. NIETSCHKE, Rosane G. Nascer em família : uma proposta de assistência de enfermagem para a interação familial saudável. Florianópolis, 1991. Dissertação (Mestrado em Enfermagem) - Programa de Pos-Graduação em Enfermagem, Universidade Federal de Santa Catarina.

30. PADOIM, Stela Maris de Mello. Em busca do estar melhor do ser-familiar e do ser-com-AIDS. Florianópolis, 1998. Dissertação (Mestrado em Enfermagem) - Polo Santa Maria, Programa de Pós-Graduação em Enfermagem, Universidade Federal de Santa Catarina.

31. PATR ÍCIO, Zuleica Maria. Cuidando e desenvolvendo um marco conceitual com a família da adolescente grávida solteira e seu recém-nascido. Florianópolis, 1990. Dissertação (Mestrado em Enfermagem) - Programa de PósGraduação em Enfermagem, Universidade Federal de Santa Catarina.

32. PELZER, Marlene Teda. Enfermeiro cuidando do idoso com Alzheimer em família.. Florianópolis, 1993. Dissetação (Mestrado em Enfermagem) - Programa de Pós-Graduação em Enfermagem, Universidade Federal de Santa Catarina.

33. PENNA, Claudia M.M. Repensando o pensar: análise crítica de um referencial teórico em enfermagem para a família. Florianópolis, 1992. Dissertação (Mestrado em Enfermagem) - Programa de Pós-Graduação em Enfermagem, Universidade Federal de Santa Catarina.

34. RIBEIRO, Ivete Maria. Interação: a enfermagem assistindo a família da criança maltratada. Florianópolis, 1990. Dissertação (Mestrado em Enfermagem) - Programa de Pós-G raduação em Enfermagem, Universidade Federal de Santa Catarina.

35. SANDRI, J uliana Vieira. Prática Assistencial de Enfermagem : a pessoa idosa e sem família com vistas ao resgate da sua cidadania utilizando a Teoria de Betty Newamm. Florianópolis, 1997. Dissertação (Mestrado em Enfermagem) Programa de Pós-Graduação em Enfermagem, Universidade Federal de Santa Catarina.

36. SILVA, Mara R. Santos da. Família e alcoolismo: em busca do conhecimento. Florianópolis, 1996. Dissertação (Mestrado em Enfermagem) - Programa de Pós-Graduação em Enfermagem, Universidade Federal de Santa Catarina.

37. SANTOS, Odaléa M. Bruggemann. A enfermagem como diálogo vivo: uma proposta humanística no cuidado à mulher e a família durante o processo do nascimento. Florianópolis, 1998. Dissertação (Mestrado em Enfermagem) - Programa de Pós-Graduação em Enfermagem, Universidade Federal de Santa Catarina.

38. SCHWARTZ, Eda. Família teuto-gaúcha: o cuidado entre possibilidades e limites. Florianópolis, 1998. Dissertação (Mestrado em Enfermagem - REPENSUL) - Programa de Pós-Graduação em Enfermagem, Universidade Federal de Santa Catarina.

39. TREVISAN, Eleonor. Cuidado à criança diabética, na teia da vida. Curitiba, 1998. Dissertação (Mestrado em Enfermagem - Polo UFPR ) - Programa de Pós-Graduação em Enfermagem, Universidade Federal de Santa Catarina.

40. WAIDMAN,M. A. P. Enfermeira e família compartilhando o processo de reinserção social do doente mental. Curitiba,1998. Dissertação (Mestrado em Enfermagem) - Programa de Pós-Graduação em Enfermagem, Universidade Federal de Santa Catarina.

41. WHALL, Ann L. LVELAND-CHERRY, Carol J . Family unit-focused reseach: 1984-1991. Annual Review of Nursing, v.11, p.227-247, 1993.

42. WR IGT, Lorraine M., LEAKEY, Trends in nursing of families. J ournal Advanced Nursing, Oxford, n.15, p.148-154, 1990. 